\title{
La cultura funeraria de las comunidades indígenas de México y el imaginario religioso
} mesoamericano

The funeral culture of the indigenous communities of Mexico and the Mesoamerican riligious imagination A cultura funerária das comunidades indígenas do México e o imaginário religioso mesoamericano

\section{Resumen}

No obstante el embate histórico de la cultura occidental y de la evangelización católica, las comunidades indígenas de México preservaron, en su tradición oral y en su cultura funeraria, dos premisas básicas del imaginario religioso mesoamericano: la concepción de la dualidad vida/ muerte y de la dualidad cuerpo/ánima. Periódicamente y al margen de la liturgia católica, llevan a cabo sui géneris rituales, donde instituyen
Alma Patricia Barbosa Sánchez lunatzin@yahoo.com Recibido: 6 de junio 2016 Aprobado: 3 de octubre 2016

una comunicación y colaboración con los difuntos. Los testimonios orales exponen la concepción del mundo sobrenatural y la existencia de los difuntos, dentro de las premisas básica del imaginario religioso mesoamericano.

Palabras clave: imaginario religioso, comunidades indígenas, México. 


\section{Abstract:}

In spite of the historical brunt of Western culture and catholic evangelization, the Mexican indigenous communities preserved, within their oral tradition and funerary culture, two basic premises of the Mesoamerican religious imaginary: the conception of life/death duality and the body/soul duality. Periodically, and on the fringes of Catholic liturgy, they perform sui géneris rituals, where they establish a communication and collaboration with the deceased. Oral testimonies explain the conception of the supernatural world, as well as the existence of the deceased, within the basic premises of the Mesoamerican religious imaginary.

Keywords: religious imaginary, indigenous communities, Mexico.

\section{Resumo}

A pesar do embate histórico da cultura ocidental e da evangelização católica, as comunidades indígenas do México preservaram, na sua tradição oral e na sua cultura funerária, duas premissas básicas do imaginário religioso mesoamericano: a concepção da dualidade vida/morte e da dualidade corpo/alma. Periodicamente e à margem da liturgia católica, realizam sui géneris rituais em que instituem uma comunicação e colaboração com os defuntos. Os testemunhos orais expõem a concepção do mundo sobrenatural e a existência dos defuntos dentro das premissas básicas do imaginário religioso mesoamericano.

Palavras chave: imaginário religioso, comunidades indígenas, México

\section{Introducción}

No obstante el embate histórico de la cultura occidental y de la evangelización católica, las comunidades indígenas de México preservaron en su tradición oral y cultura funeraria los fundamentos básicos del imaginario ${ }^{1}$ religioso mesoamericano, toda vez que, periódicamente, llevan a cabo sui géneris rituales funerarios que encuentran su sentido y origen en la concepción religiosa mesoamericana referida a la dualidad vida/muerte y la dualidad cuerpo/ánima al margen de la liturgia católica. Dentro del pensamiento e imaginario religioso mesoamericano, la

1 Castoriadis (1998) plantea que el psiquismo humano posee una imaginación radical capaz de crear, superando las limitaciones de repetir o sólo de imitar. Durand (2004) define al imaginario como: "el conjunto de las imágenes y las relaciones de imágenes que constituye el capital pensante del homo sapiens" (p. 21). 
dualidad vida/muerte se manifiesta como un proceso dialéctico y de retroalimentación, en el que la muerte da origen a la vida y viceversa. La vida está contenida en el principio de muerte, así como la muerte está contenida en el principio de vida. La retroalimentación mutua de estos dos principios equivale a la función alimenticia que realizan los seres vivos que se nutren de la muerte de otros seres, al igual que, en las ceremonias rituales, el sacrifico humano era significado como alimento de las deidades, garantes de la existencia de todo ser.

La muerte y su contexto sobrenatural constituyen temas preponderantes en el imaginario religioso mesoamericano, que dan origen a la práctica de complejos ritos cuando fallece el individuo y durante la conmemoración de su deceso. Como en otras culturas, el paradigma de la dualidad cuerpo/ánima constituye una postura que atenúa la angustia que genera la certeza y conciencia de la muerte, toda vez que plantea la existencia sobrenatural de la persona más allá de la extinción de su cuerpo físico. Si cuerpo y ánima constituyen un binomio indisoluble de la existencia humana, ante la muerte solamente el ánima sobrevive en la dimensión sobrenatural. Por ende, en el pensamiento mesoamericano la totalidad de la persona no se extingue con la muerte, ya que su ánima asume existencia en el ámbito sobrenatural. Diego de Landa (2003) consigna esta concepción entre los mayas: "Que esta gente ha creído siempre en la inmortalidad del alma [...], porque creían que después de la muerte había otra vida más excelente de la cual gozaba el alma apartándose del cuerpo" (p. 137). Así también señala que se concebían dos formas de existencia de los difuntos: la primera, "buena y deleitosa para los que hubiesen vivido bien su manera de vivir" (p. 137), con abundancia de alimentos y bebidas de mucha dulzura y "un árbol que allá llaman yaxche, muy fresco y de gran sombra, que es (una) ceiba, debajo de cuyas ramas y sombra descansarían y holgarían todos siempre" (p. 137). Para los que habían asumido 


\section{SIWÔ `' Volumen 9, Números 1, 2015}

un comportamiento vicioso e incorrecto les aguardaba una existencia subterránea, con hambre, frío, cansancio y tristeza. ( $\mathrm{p}$. 137). Sin embargo, Mercedes de la Garza (1990) señala que las fuentes de los mayas no plantean que la idea de premio o castigo determine el lugar de destino de los difuntos, "sino que la mayoría de los cronistas expone sólo su propia interpretación cristiana” (p. 93), para explicar que al primer sitio iban los buenos y al segundo los malos.

El proceso que seguía al desprendimiento del ánima del cuerpo post mortem se inscribe dentro de un marco temporal, ya que la cronología religiosa contabilizaba los periodos en los cuales el ánima arribaba a su destino final, ya sean ochenta días, para la que se dirigía hacia el Cielo del Sol, o de cuatro años, para la que se dirigía al Mictlan: "lugar de los muertos" (López Austin, 1990: 366). Así también, se concebía que después de la cremación de los que fallecían por enfermedad, el ánima "quedaba cuatro días más sobre la superficie de la tierra, terminados los cuales iniciaba su camino al Mictlan" (López Austin, 1990: 364). De igual manera ocurría con el ánima de los difuntos infantes (López Austin, 1990: 365).

Los espacios destinados a las ánimas de los difuntos abarcan: el "Mictlan, para los que fallecían de muerte común; Tonátiuh Ilhuícatl o Cielo del Sol, para los caídos en combate, los sacrificados al Sol y las muertas en primer parto; el Tlalocan, para los que fallecían por alguna causa relacionada con el agua, y el Chichihualcuauhco, para los aún lactantes" (López Austin, 1990: 363). Este último se caracteriza por la presencia de un árbol nodriza, del cual penden mamas que alimentan a las ánimas de los difuntos infantes (López Austin, 1990: 384).

En el imaginario maya, el cielo aguardaba a los que fallecían sacrificados; el paraíso de la abundancia a los que morían 
ahogados o por circunstancias relacionadas con el agua; el Xibalbá (inframundo), para los que fallecían de forma común; y el paraíso de la diosa Ixtab, a los que cometían suicidio, ahorcándose. Cuando el destino de los difuntos era el Mictlan, sus ánimas asumían una actividad viajera y el desafío de afrontar y vencer distintos obstáculos durante su tránsito; si sus esfuerzos fracasaban, ocurría su desaparición. Esta idea de la muerte como un viaje sobrenatural, con obstáculos y pruebas por superar, también está presente en el imaginario maya, "aunque no mencionada en las fuentes coloniales del área maya, pero sí en la literatura quiché" (Ruz Lhuillier, 1968: 77). A partir de estas concepciones del imaginario religioso mesoamericano, se explica el habitus ${ }^{2}$ ritual en la cultura funeraria de las comunidades indígenas de México.

\section{Dualidad vida/muerte}

La ofrenda de bienes alimenticios, velas, flores y aromas al difunto constituye una constante en las ceremonias funerarias de las actuales comunidades indígenas, que significa la retroalimentación entre la vida y la muerte, como plantea la antigua concepción mesoamericana. Si la vida se alimenta de la muerte de otros seres, también la muerte se nutre de la vida mediante la capacidad de los difuntos de aprovechar simbólicamente las cualidades o atributos de los bienes mundanos. La retroalimentación

2 "Los habitus se conceptualizan como productos de condicionamientos asociados a una forma particular de existencia, aun cuando poseen un carácter arbitrario, se presentan para los sujetos no sólo como necesarios, sino hasta naturales. Producto de la historia los habitus producen prácticas, individuales y colectivas. Conforme a los principios [schèmes] engendrados por la historia; aseguran la presencia activa de las experiencias pasadas que, depositan en cada organismo bajo la forma de principios [schèmes] de percepción, pensamiento y acción, aseguran con más precisión que las reglas formales y normas explícitas la consecución de las prácticas a través del tiempo" (Bourdieu, 1991: 94-95). 


\section{SIWÔ ’ Volumen 9, Números 1, 2015}

vida/muerte forma parte del intercambio simbólico entre la comunidad viviente y su contraparte difunta.

A través de las ofrendas los difuntos reciben el auxilio ritual de los vivientes, ya que el mundo sobrenatural no los exime de la necesidad de contar con alimento simbólico. A su vez, los vivientes son auxiliados por los difuntos mediante su tutela y atributo de potenciar la fertilidad agrícola desde el ámbito telúrico. Así por ejemplo, en la población de Morelos, la abundancia o no de las ofrendas funerarias del mes de noviembre es correspondiente a la de las cosechas, ya que los difuntos son corresponsables de la productividad agrícola. Por ende, las ofrendas propician la fertilidad agrícola en colaboración con los difuntos.

Particularmente, en el proceso de evangelización católica, las comunidades indígenas encontraron en las ceremonias de Todos los Santos y Fieles Difuntos la ocasión de preservar el sentido de su ritualidad funeraria, a través de la doble conmemoración de los difuntos -tanto infantes como adultos- y la práctica de las ofrendas funerarias. Este hecho fue advertido por cronistas como Durán, que consigna: "A mí me pesó porque vi de patentemente celebrar la fiesta de difuntos chica y grande y ofrecer en la una dinero y cacao, ceras aves y fruta, semillas en cantidad y cosas de comida y otro día vi de hacer lo mismo y aunque esta fiesta caía por Agosto lo que imagino es que si alguna simulación hay o mal respeto (lo cual yo no osaré afirmar) que lo han pasado aquella fiesta de los Santos para disimular su mal en lo que toca a este ceremonia" (Durán, 2001: 269).

A partir de la ceremonia católica del 2 de noviembre, las comunidades indígenas adoptaron un periodo más amplio para honrar a sus difuntos que tipifica sus particularidades: los niños que fueron bautizados o no; los adultos que fallecieron por accidente o por enfermedad; y los difuntos que ya no cuentan con 
familia, esto es, las ánimas solas. Actualmente, cada comunidad instaura su propia periodización a partir de su reinterpretación simbólica del imaginario mesoamericano dentro de su tradición local o regional; de ahí la diversidad de fechas conmemorativas en el país.

La dualidad vida/muerte se proyecta en la noción de comunidad, al concebirse que su totalidad se constituye con la parte viviente y su contraparte difunta, ya que el imaginario dota a los difuntos de una existencia sobrenatural y actuante que les permite representar una comunidad, específicamente, sobrenatural, en coexistencia con la comunidad viviente. Por ende, la relación entre la comunidad viviente y difunta se instaura como un proceso dinámico y de interacción mediante la reciprocidad, la colaboración mutua o la confrontación. Mientras que la comunidad viviente auxilia a los difuntos a través de la ritualidad funeraria -ofrendas, rezos, cantos, velaciones, conmemoraciones, etcétera-, la comunidad difunta corresponde a los vivientes con una función de tutela y apoyo, ya sea colaborando en el buen desarrollo de los ciclos de la productividad agrícola o intercediendo ante las divinidades por el bienestar de la familia y la comunidad. Por el contrario, cuando la comunidad viviente omite el auxilio ritual y el intercambio simbólico con los difuntos, éstos no cesarán de corresponder con agravios, ya sea introduciéndose en el cuerpo de un ser viviente (fenómeno denominado "colgarse"), manifestando su reclamo en los sueños o provocando el espanto o la muerte, entre otros. En esta lógica simbólica, la relación entre la comunidad viviente y difunta no solo se manifiesta como un vínculo subjetivo, filial, simbólico y ritual, sino también con un sentido pragmático, ya que los actores sociales consideran que los difuntos intervienen activamente en el desarrollo de su bienestar personal y en el de la colectividad. Los testimonios afirman: 
Porque no crea que, porque ya murieron, ellos no están aquí. Ellos están, nomás que no nos hacen daño, porque dijo Dios. ¿Si los vemos? ¿Qué haríamos? Si nomás, con un temblor ya estamos que unos se privan, les agarra infarto, se mueren. Qué tal si vemos a nuestra persona que nos está hablando su esqueleto: no vamos a aguantar. Dijo Dios: va a ser todo oculto. (Reina Octaviano Onofre. Entrevista personal, 2 de noviembre de 2008)

Sin duda la subjetividad colectiva asume predisposiciones, actitudes y acciones ante los difuntos y su influencia en la vida social. La relevancia de su tutela en la problemática de los actores rituales se consigna en los siguientes testimonios. "Mientras aquí, en la tierra, les hacemos todos sus honores, con una creencia de que sí, sí nos andan viendo cómo nos portamos" (Bernabé Pérez Romero. Entrevista personal. 15 de noviembre de 2008.). "Yo me refugio en ellos. Les pido que me ayuden, ellos que están más cerca de Dios”. (Anastasia Santibáñez Ramírez. Entrevista personal. 15 de noviembre de 2008). "Al llegar con Dios, ellos están bien conscientes, son obedientes. Si tú les dices: mira, me duele mi ojo, tengo cansancio, me duelen mis pies, ellos me lo quitan. Mi señor estaba malo de la próstata, se le quitó, le mandaron su alivio" (Reina Octaviano Onofre, 2 de noviembre de 2008).

En la comunidad de tacuates (Santa María Zacatepec, Oaxaca), se consigna la función protectora de los difuntos, ya que: "Se cree que los muertos tienen poderes y que, si uno les pide algo, ellos seguramente lo cumplirán" (Castillo Cisneros, 2006: 41). Las comunidades mayas plantean que los espíritus de los difuntos vagan por el paisaje, con una función de protección hacia los vivientes, "ya que están allí para proteger y hasta alertar a sus familiares de algún peligro" (Ruz Lhuillier, 2006: 53). La comunidad yucateca de Dzoyaxché afirma que "las madres muertas vienen por las noches a lavar la ropa de los huérfanos que el viudo descuida" (Ruz, 2003: 620). 
Los huastecos de Tancuime, San Luis Potosí, asumen que las ánimas de los difuntos acceden favorablemente a sus peticiones de ayuda, a cambio de las oraciones que necesitan para salir rápido de su condición penitente. De ahí que los vivientes consideren que las ánimas de los difuntos constituyen la primera instancia de ayuda sobrenatural, toda vez que los santos no hacen caso a sus peticiones, ya que, al gozar del cielo ya no necesitan oraciones (Ruz, 2005: 544). En Guerrero, los actores rituales dirigen su solicitud de ayuda directamente a la osamenta del difunto; Catharine Good (2004) consigna: "Me han dicho que antes guardaban los huesos en sus casas y que los cráneos a veces servían para dar consejos, para resolver problemas o lograr objetivos, al darles un uso oracular" (p. 169). Estos testimonios ejemplifican la íntima relación entre los vivientes y los difuntos, a partir de una colaboración mutua, dentro de la concepción de la dualidad vida-muerte mesoamericana.

\section{La dualidad cuerpo/ánima}

Al margen de la liturgia católica, las comunidades indígenas realizan sui géneris rituales funerarios que encuentran sentido y origen en la concepción religiosa mesoamericana. Así, por ejemplo, llevan a cabo dos rituales de entierro, esto es, el del cuerpo y, nueve días después, el del ánima del difunto, denominada sombra. Este procedimiento evoca la concepción de la dualidad cuerpo/ánima dentro del antiguo imaginario funerario nahua, donde se concebía que, con la muerte, el ánima del difunto se desprendía del cuerpo y permanecía un cierto tiempo en el ámbito terrenal, antes de emprender su viaje al lugar que le correspondía en el mundo sobrenatural. De ahí el sentido actual del auxilio ritual a la estancia del ánima durante el periodo de nueve días. Esta lógica ritual presupone que, al fallecer el 


\section{SIWÔ ’ Volumen 9, Números 1, 2015}

individuo, su sombra requiere de un cuerpo sustituto y simbólico donde albergarse durante su estancia en el hogar de sus deudos. Por esta razón, los familiares proceden a trazar sobre el piso un signo de cruz con arena, cal y flores, que representa el albergue o cuerpo simbólico, donde la sombra reposará durante el novenario, en tanto que los actores rituales la arropan y velan mediante cantos, rezos colectivos y ofrendas alimenticias. Al finalizar este periodo, se procede a realizar la ceremonia de "levantar la cruz" o "levantar la sombra", donde simbólicamente los deudos trasladan el ánima al cementerio para enterrarla en el sepulcro de su propietario. Este procedimiento ritual se fundamenta en el imaginario religioso mesoamericano, donde la dualidad cuerpo/ ánima constituía una postura que atenuaba la angustia que genera la certeza y conciencia de la muerte, toda vez la persona no se extinguía con la muerte, ya que su ánima asumía existencia en el ámbito sobrenatural. Así, por ejemplo, el cuerpo post mortem recibía un tratamiento simbólico al ser objeto de conversación por parte de los deudos, en tanto que se consideraba que su entidad anímica no estaba ausente (Durán, 2002: 451). El testimonio de Clavijero (1968) reitera que si un señor: "moría se proseguía hablando de él como si estuviese aún vivo" (p. 200). En esta práctica subyace la idea de que la entidad anímica del difunto estaba presente en su cuerpo post mortem hasta que éste fuese cremado, lapso de tiempo en el cual el difunto era capaz de percibir su entorno.

Actualmente las comunidades indígenas preservan este habitus ritual, como ejemplifican los siguientes testimonios orales que afirman: "Yo sé que ellos, aunque su cuerpo está muerto, su espíritu está vivo y siente y escucha todo lo que está pasando a su alrededor" (Josefina Román. Entrevista personal, 2 de noviembre de 2007). "Dicen que, en casa de uno, siguen escuchando. Como quien dice, si ya no lo viste, ya no se despidió de ti o ya no te dio la bendición, ya uno platica con ellos, que ya no se 
vaya con el pendiente. Platicas ahí, con él. Todavía puede oír su misa. Ya, saliendo de la iglesia, ya no. Ya como quien dice, ya le taparon los oídos" (Rosario Saldaña. Entrevista personal, 2 de noviembre de 2007).

Otro procedimiento ritual consiste en acompañar el cuerpo post mortem con su ajuar funerario, que ya su función simbólica es proveer al difunto de lo necesario durante su tránsito por los territorios inhóspitos del más allá. De ahí que en el ataúd se coloque una dotación de ropa para su abrigo, huaraches tradicionales, como protección contra las piedras y espinas del camino, una vara que sirve como báculo, un cordón para asirse y escalar obstáculos, una vela para alumbrar su camino, una dotación de alimentos y agua para su consumo, y como obsequio para sus parientes difuntos, una dotación de tequesquite y hojas de maíz como alimento para los fieros animales sobrenaturales que encontrará en su trayecto, "gorditas" de maíz para agradecer al pequeño perro que lo ayudará a cruzar el caudaloso río sobrenatural, y dinero para sufragar sus gastos en el más allá, entre otros elementos.

Cada uno de estos elementos tiene un sentido de pertinencia primordial dentro de la concepción de la muerte como metáfora de un viaje sobrenatural no exento de peligros. Si la antigua ritualidad funeraria nahua arropaba en exceso al difunto, previendo la extrema frialdad del viento sobrenatural, en la actualidad, la ropa, en el ajuar funerario, se justifica como provisión y muda. Los testimonios morelenses afirman:

Siempre acostumbramos a ponerles ropa, porque dicen que es para su camino. Como uno, cuando sale de viaje, pues, uno aparte de la ropa que lleva puesta, por lo menos, lleva una muda. Porque uno sabe que se va a quedar un día, dos días, y para cambiarme, para el regreso, así es para estas personas. Y uno tiene que ponerle su ropita, para que se vayan, 
en el camino; ya sea la ropa que usaban o que más les gustaba o la más nuevecita. Se les pone ahí, en el ataúd. (Jacqueline Vázquez Morán. Comunicación personal, 2 de noviembre de 2008)

En la caja va su ropita. Hay unas personas que la tienden abajo, como colchoncito. Y ya la demás, si tiene más, mucha ropa, la doblamos y le ponemos de cabecerita. Eso dicen, que se llevan sus ropas, porque a largo tiempo, dicen que piden la ropa. Piden sus ropas, porque se les acaba en la otra vida. (María Isabel Nepomuceno Linares. Entrevista personal, 2 de noviembre de 2008)

En algunas comunidades se enfatiza la solidaridad con la comunidad difunta, ya que la provisión de alimentos, en el ajuar funerario, también está destinada al consumo de los parientes fallecidos:

El difunto lleva para que coma toda su gente, los que conoce allá, a sus amigos. También hacemos doce gorditas para nuestra mamá, si ya se murió, papá, hermano, tío, qué sé yo. Allá, llega y harta "gorda", con trabajos la saca. Aquí, nomás, son doce. Allá, son hartas. Mandamos de comer de aquí, para allá, con el difuntito. Sí, a su mamá, a su papá, a sus hermanos. Porque, a veces, se adelantan hartos y se les manda a los abuelitos, las abuelitas, tatarabuelitas, todos esos que ya están allá. El difunto llega y les da de hasta tres gorditas. Se le pone pan, según los abuelitos anteriores, el pan de torta. Le ponemos, porque dicen que allá no tiene, a veces, para un pan, el pobre que muere aquí. El difunto reparte pan con hartos pa' que les dé a todos sus amiguitos que tiene ahí, se comparte. (Octaviano Onofre, Reina. Entrevista personal. 2 de noviembre de 2008)

El ajuar funerario de los difuntos infantes mantiene correspondencia con su edad y hábitos, incluyendo objetos de formato diminuto y juguetes. Así, en Tepoztlán, Morelos, el ajuar funerario de los niños se caracteriza por el "bule chiquito, una jicarita, 
su palmita, sus huarachitos de cartón, con su listón, los juguetes que jugaba con ellos; y los visten de algún santito" (Conde Mendoza, Josefina. Entrevista personal, 2 de noviembre de 2008).

Un caso singular ocurre en la comunidad mixteca de tacuates, en Santa María Zacatepec, Oaxaca, donde se entierran espejos junto al cadáver, con una función simbólica sumamente particular, ya que el imaginario funerario dicta que se pueden utilizar para vengar los asesinatos. Con este propósito:

(...) entierran al difunto con espejos y eso hace que quienes lo mataron no descansen, pues, cada vez que el asesino ve el agua, ve reflejada la imagen del muerto; esto poco a poco los vuelve locos hasta que se quitan la vida. También pueden colocar listones en la espalda del difunto con el nombre de los homicidas, y el muerto hace que éstos 'caigan rápido'. (Castillo Cisneros, 2006: 41)

Si el antiguo imaginario nahua plantea que, en su viaje sobrenatural, los difuntos confrontan seres fantásticos como la culebra y la "lagartija que se dice xochitonal" (Sahagún, 1992: 206), el imaginario actual procede a una reinterpretación de esta premisa, ya que los difuntos enfrentan animales domésticos que, no obstante, mantienen la significación de fiereza y peligro. En esta perspectiva, se dota al difunto de alimento destinado a aplacar a estos seres fantásticos; en tanto que éstos se alimentan, él difunto puede seguir su camino. Por ejemplo, en Xantetelco, Morelos, el ajuar funerario incluye tiras de hoja de mazorca como alimento para los animales sobrenaturales que, en este caso, se identifican con los que el individuo consumió en vida:

Se dice que ahorita, comemos carne de res, comemos carne de puerco, y entonces, ya para irse ahí, a otro mundo, lo que comimos: ya lo vemos, como animal ahí. Entonces, ya no confronta el alma al animal. Entonces, lo que comimos, todo vemos ahí. Entonces, la hoja de la mazorca se raja 
delgada y, en una jicarita nueva, se llena y la ponen a un lado del difunto. Con esto, se defiende, cuando ve al caballo, al buey, agarra su hoja de mazorca, la avienta a los animales, mientras comen, él pasa. (Luisa Vargas Linares. Entrevista personal, 2 de noviembre de 2007).

En algunas comunidades, los testimonios evocan con mayor nitidez el antiguo imaginario mesoamericano que plantea el auxilio que brinda un pequeño perro bermejo, para ayudar a los difuntos a cruzar el caudal del río sobrenatural. De ahí que, en estas comunidades, el ajuar funerario incluya una dotación de "gorditas" de maíz, para cumplir con el intercambio simbólico con estos pequeños perros sobrenaturales. Un testimonio afirma:

Cuando ya vas allá, nos pasan hartas cosas. Cuando ya vas en el río ancho y tú no puedes pasar, porque ves que se va el agua muy feo a un lado; hartos ven cómo se pasan, se atreven y ya no aparecen. Entonces, el difunto no se pasa, está llorando. Si tiene un perro que lo quiso, ese perrito va y le dice: - ¿Por qué lloras? Aquí, en esta vida, cuándo vemos a un perrito que nos habla: nunca. -iPor qué lloras? -Yo me quiero pasar, ya me tengo que ir, ya es tarde, ya va a oscurecer y no me puedo pasar. - ¡Ah, no llores, yo te voy a pasar! ¿No te acuerdas que fuiste mi amo? -No, ya no me acuerdo. Ya se me olvidó. -¡Pero yo sí me acuerdo, te estoy esperando porque sé muy bien que te voy a pasar, en este lugar! Porque tú me amaste en la vida, me diste de comer. A donde te ibas, yo te seguía. Agárrate de mi orejita y nos vamos a pasar. Y el difunto se agarra de la orejita del perrito. Y cuando viene el agua, él se avienta y el difunto, como no pesa, se avienta con todo y todo. El perrito va con el difunto arriba, va nadando. "Tú no temas", te dice el perrito: "Agárrate de mi orejita". Y te lleva y ya pasas el río ancho. Y el perrito te pasa, es tu defensa. Como dicen, el perrito es tu amigo fiel. (Reina Octaviano Onofre. Entrevista personal. 2 de noviembre de 2008) 
Los testimonios orales dan cuenta de las circunstancias que enfrentan los difuntos, ya que a través de los sueños "revelan" los avatares de su viaje sobrenatural, tanto en el caso de ser provistos con su ajuar funerario como de no contar con éste. Así se afirma:

Y entonces, después, en la noche, reveló en un sueño: que gracias que le habíamos puesto huaraches. Porque dice que ella, cuando iba en el camino: son puros pedregales. Y contó que al difunto que había fallecido cuatro días después que ella, que a ese señor, que no le pusieron nada de esas cosas ni ropa ni huaraches ni varita ni palma ni vela. Y ella dice que él iba sufriendo, porque no tenía luz para alumbrarse y no llevaba huaraches; ya no podía ni caminar, que sus pies iban lastimados. Y ella llegó más primero a donde, creo yo, ya le tocaba. Y llegó. Y él todavía tenía que seguir, caminando su camino. Y entonces, ella llegó. Y ella iba, con su vara, deteniéndose y con todo lo que necesitaba, en el camino. Y este señor no llevaba nada y ya iba bien apurado. Y ella le dice: "Vente detrás de mí y yo te voy alumbrando, con mi vela". (Patricia Sánchez Avelar. Entrevista personal, 2 de noviembre de 2007)

El ámbito onírico permite la comunicación y convivencia entre vivientes y difuntos.

La significación de los sueños constituye una tradición cultural que se remonta a las sociedades mesoamericanas y que, en la actualidad, no ha perdido vigencia. Por este medio, los actores rituales norman sus acciones e interpretan los requerimientos de los difuntos.

Mi mamá, recién que ella falleció, ella tenía muchos pollos, marranitos, conejos. Tenía bastantitos animales. Y cuando ella ya no estuvo, como yo trabajo en la costura aparte del hogar, dije, no, pues, voy a regalar los animales. Y los regalé, por aquí pollos, por aquí marranitos y me deshice de todos. Y de ahí empezó un calvario hacia mí, porque yo la soñaba y la soñaba. Y cuando yo la veía que llegaba, en mis sueños, 
yo decía: qué le voy a decir de los pollos, qué le voy a decir de sus animales, lo que les hice a sus animales. Pues, yo sabía que ella se había ido o que ella ya no estaba. (González, Gloria. Entrevista personal, 2 de noviembre de 2008)

El impacto del protestantismo entre las comunidades indígenas es un aspecto por considerar, ya que no solo ha generado la división ideológica entre sus miembros, también ha propiciado la reafirmación del imaginario funerario mediante la subjetividad onírica, esto es, de los sueños, donde los difuntos que en vida desertaron del catolicismo y adoptaron el protestantismo comunican su penar por la omisión del auxilio ritual. De ahí que el imaginario funerario evidencie su capacidad de adaptarse y legitimarse ante nuevas circunstancias culturales, toda vez que su sistema de penalización detenta una eficacia simbólica al prevalecer el temor de los actores rituales al padecimiento de los difuntos por la omisión ritual, como describe el siguiente testimonio:

El año pasado falleció mi suegra. Mi suegra ya era de otra religión. Y ella siempre me dijo que no le rezara, que no quería. Y yo le recé aquí, pero no tendí la cruz, porque ella me dijo que no le tendiera. Ahí puse una cruz de veladoras y todas las noches le rezaba, con mis hijos. No invité a nadie. Según la creencia que tengo, que si no rezaba, ella no descansa. Pero una concuña la soñó. Y dice que, en el sueño, le pidió que levantara la cruz, que levantara su sombra. Pero yo sí le voy a rezar, y voy a tender su cruz, y sí se la voy a levantar, porque yo creo que, si no, no descansa. (María del Carmen Cisneros Pérez. Entrevista personal, 2 de noviembre de 2008)

Cuando los actores rituales omiten las ofrendas a los difuntos, la tradición oral, en varias regiones de México, consigna un mismo relato acerca de las consecuencias funestas que ocasiona la omisión de la ofrenda funeraria a los difuntos. Los actores rituales, generalmente del género masculino, se rehúsan 
a colaborar con los bienes destinados a la ofrenda, en contradicción con los personajes femeninos, que siempre se muestran dispuestos a rendir los honores a los difuntos. Desafiando la tradición, los personajes masculinos ofrendan piedras, boñiga o un trozo de ocote. Al realizar su faena en el campo, éstos observan la procesión de los difuntos durante su regreso al más allá, así como a sus familiares llevando la ofrenda de boñiga, estiércol y ocote. Generalmente, el relato finaliza con la muerte de los infractores rituales, como sanción a su negativa de colaboración ritual.

Es patente que los testimonios de la tradición oral constituyen la materialización del imaginario religioso de las comunidades indígenas, donde se advierten los fundamentos básicos de la religión mesoamericana.

\section{Conclusiones:}

En general, la tradición oral y el habitus ritual de las actuales comunidades indígenas han preservado dos fundamentos básicos del imaginario religioso mesoamericano: la dualidad vida/muerte y de la dualidad cuerpo/ánima. De ahí que los relatos orales describan la coexistencia de seres vivientes y difuntos dentro de una relación de retroalimentación, interdependencia, colaboración o confrontación. Cabe destacar que la reflexión epistemológica ha considerado que si bien la tradición oral y el habitus ritual indígenas han constituido recursos históricos de resistencia y transmisión del imaginario funerario mesoamericano, su acervo de concepciones y de procedimientos rituales no ha estado exento del proceso de reelaboración simbólica por parte de las comunidades indígenas en función de su contexto histórico y de las particularidades de su cultura regional o bien, del impacto del sincretismo religioso. De ahí que la tradición oral ejemplifique esta reelaboración simbólica, ya que no se ha limitado a 


\section{SIWÔ ’ Volumen 9, Números 1, 2015}

la estricta transmisión de relatos, sino que ha constituido una fuente de constante producción de sentido y de significación a partir de la subjetividad colectiva que da cuenta de la existencia sobrenatural de los difuntos, sus oficios, sus filias, sus fobias, su colaboración o confrontación con los vivientes, su comportamiento durante sus visitas periódicas a los que fueron sus hogares y su participación en el banquete funerario, entre otros.

Paralelamente, las modalidades de procedimiento que asume el habitus ritual escenifican las variantes conceptuales de la reelaboración y reinterpretación simbólica del imaginario funerario que cada comunidad instaura en su cultura regional o local.

\section{Referencias bibliográficas}

Bourdieu, Pierre. El sentido práctico. Madrid: Taurus Humanidades, 1991. Impreso.

Castoriadis, Cornelius. Hecho y por hace. Pensar la imaginación. Buenos Aires: Eudeba-Universidad de Buenos Aires, Argentina, 1998. Impreso.

Castillo Cisneros, María del Carmen,. Tacuates. Pueblos indígenas del México contemporáneo. México: Comisión Nacional para el Desarrollo de los Pueblos Indígenas, 2006. Impreso.

Clavijero, Francisco Javier. Historia antigua de México. México: Porrúa, 1968. Impreso.

Cisneros Pérez, M. C. Comunicación personal, 2 de noviembre de 2008.

Durán, Fray Diego. Historia de las Indias de Nueva España e Islas de Tierra Firme, t. I. México: CONACULTA, 2001. Impreso.

Durand, Gilbert. Las estructuras antropológicas del imaginario. Introducción a la arquetipología general. México: Fondo de Cultura Económica, 2004. Impreso. 
Garza, Mercedes de la. El hombre en el pensamiento religioso náhuatl y maya. México: Instituto de Investigaciones $\mathrm{Fi}$ lológicas, UNAM, 1990. Impreso.

Good Eshelman, Catherine. "Trabajando juntos: los vivos, los muertos, la tierra y el maíz". Historia y vida ceremonial en las comunidades mesoamericanas: los ritos agrícolas, Broda, Johanna y Good Eshelman Catharine (comp.). México: INAH-UNAM, 2004. Impreso.

Gómara, Francisco López de. Historia de la Conquista de México. México: Porrúa, 1997. Impreso.

Gómez, Pedro Arturo. (2001). "Imaginarios sociales y análisis semiótico. Una aproximación a la construcción narrativa de la realidad". Cuadernos 17 (2001): 195-209. Impreso.

Landa, Fray Diego de. Relación de las cosas de Yucatán, México: CONACULTA, 2003. Impreso.

López Austin, Alfredo. Cuerpo humano e ideología. Las concepciones de los antiguos nahuas, t. I. México: Fondo de Cultura Económica, 1996. Impreso.

Pozas Arciniega, Ricardo. Chamula, México: Colección INI, 1987. Impreso.

Ruz, Mario Humberto. Mayas. Segunda parte. Pueblos indígenas del México contemporáneo. México: Comisión Nacional para el Desarrollo de los Pueblos Indígenas-Programa de las Naciones Unidas para el Desarrollo, 2006. Impreso.

"Paisajes de muerte, paisajes de eternidad". Espacios mayas, usos representaciones, creencias. Alain Breton, Aurora Monod Bequela, Mario Humberto Ruz (comp.). México: Centro de Estudios Mayas, IIFL, UNAM, Centro Francés de Estudios Mexicanos y Centroamericanos, 2003. Impreso.

'Cada uno con su costumbra'. Memoria y olvido en los cultos funerarios contemporáneos". La muerte en la cultura maya. Antropología de la eternidad. Andrés Ciudad Ruiz, Mario 
Humberto Ruz, María Josefa Iglesias Ponce de León (comp). México: Sociedad Española de Estudios Mayas, Universidad Nacional Autónoma de México, 2005. Impreso.

Ruz Lhuillier, Alberto. Costumbres funerarias de los antiguos mayas. México: Seminario de Cultura Maya, Universidad Nacional Autónoma de México, 1968. Impreso.

Sahagún, Fray Bernardino. Historia general de las cosas de Nueva España. México: Porrúa, 1992. Impreso.

\section{Entrevistas}

Cisneros Pérez, María del Carmen. Entrevista personal, 2 de noviembre de 2008.

Conde Mendoza, Josefina. Entrevista personal, 2 de noviembre de 2008.

González, Gloria. Entrevista personal. 2 de noviembre de 2008.

Nepomuceno Linares, María Isabel. Entrevista personal, 2 de noviembre de 2008.

Octaviano Onofre, Reina. Entrevista personal, 2 de noviembre de 2008.

Pérez Romero, Bernabé. Entrevista personal, 15 de noviembre de 2008.

Román, Josefina. Entrevista personal, 2 de noviembre de 2007.

Sánchez Avelar, Patricia. Entrevista personal, 2 de noviembre de 2007.

Santibáñez Ramírez, Anastasia. Entrevista personal. 15 de noviembre de 2008

Saldaña, Rosario. Entrevista personal, 2 de noviembre de 2007.

Vargas Linares, Luisa. Entrevista personal, 2 de noviembre de 2007. 